\title{
ARTICLE
}

Multiple myeloma gammopathies

\section{Ixazomib, lenalidomide, and dexamethasone in patients with newly diagnosed multiple myeloma: long-term follow-up including ixazomib maintenance}

\author{
Shaji K. Kumar $\mathbb{D}^{1}$ - Jesus G. Berdeja ${ }^{2} \cdot$ Ruben Niesvizky $^{3} \cdot$ Sagar Lonial $^{4} \cdot$ Jacob P. Laubach $^{5} \cdot$ Mehdi Hamadani $^{6}$. \\ A. Keith Stewart ${ }^{7} \cdot$ Parameswaran Hari $^{8} \cdot$ Vivek Roy $^{9} \cdot$ Robert Vescio $^{10} \cdot$ Jonathan L. Kaufman $^{4}$ - Deborah Berg ${ }^{11}$. \\ Eileen Liao ${ }^{11,12} \cdot$ S. Vincent Rajkumar ${ }^{1} \cdot$ Paul G. Richardson ${ }^{5}$
}

Received: 29 August 2018 / Revised: 14 December 2018 / Accepted: 24 December 2018 / Published online: 29 January 2019

(c) The Author(s) 2019. This article is published with open access

\begin{abstract}
Triplet combinations containing a proteasome inhibitor are a standard of care in newly diagnosed multiple myeloma (NDMM). We examined the long-term efficacy and safety of the all-oral combination of weekly ixazomib plus lenalidomide-dexamethasone (IRd), followed by single-agent ixazomib maintenance in NDMM patients. Of 65 enrolled patients, 53 received ixazomib $4 \mathrm{mg}$ (days 1, 8, and 15) plus lenalidomide $25 \mathrm{mg}$ (days 1-21) and dexamethasone $40 \mathrm{mg}$ (days 1, 8, 15, and 22) for up to twelve 28-day induction cycles. Twenty-three patients discontinued induction for stem cell transplantation (SCT). In the remaining 42 patients, overall response rate was $80 \%$, including $63 \% \geq \mathrm{very}$ good partial response (VGPR) and $32 \%$ complete responses. At a median follow-up of 56 months, median progression-free survival (PFS) was 35.4 months in the total population. Twenty-five patients received ixazomib maintenance; eight deepened their response ( $76 \% \geq \mathrm{VGPR})$, and median PFS was 37.2 months in this subgroup. Nine of 42 patients who did not proceed to SCT (14\% of total population) had an adverse event requiring discontinuation. Ixazomib (median $\geq 96 \%$ ) and lenalidomide (median 88-94\%) relative dose intensities were maintained throughout treatment. Weekly IRd, followed by ixazomib maintenance, was highly active with acceptable toxicity, enabling long-term administration with no evidence of cumulative toxicities.
\end{abstract}

Supplementary information The online version of this article (https:// doi.org/10.1038/s41375-019-0384-1) contains supplementary material, which is available to authorized users.

Shaji K. Kumar

kumar.shaji@mayo.edu

Mayo Clinic, Rochester, MN, USA

2 Sarah Cannon Research Institute, Nashville, TN, USA

3 Myeloma Center, Weill Cornell Medicine, New York Presbyterian Hospital, New York, NY, USA

4 Department of Hematology and Medical Oncology, Winship Cancer Institute of Emory University, Atlanta, GA, USA

5 Dana-Farber Cancer Institute, Boston, MA, USA

6 West Virginia University, Mary Babb Randolph Cancer Center, Morgantown, WV, USA

\section{Introduction}

Treatment strategies for multiple myeloma (MM) have evolved considerably over the past 15 years, influenced by a variety of different factors [1, 2]. For newly diagnosed MM (NDMM) the use of multidrug combinations for induction therapy has become a standard approach, with phase 3 trials

7 Mayo Clinic College of Medicine, Scottsdale, AZ, USA

8 Division of Hematology Oncology, Medical College of Wisconsin, Milwaukee, WI, USA

9 Mayo Clinic, Jacksonville, FL, USA

10 Cedars-Sinai Outpatient Cancer Center at the Samuel Oschin Comprehensive Cancer Institute, Los Angeles, CA, USA

11 Millennium Pharmaceuticals Inc. (a wholly owned subsidiary of Takeda Pharmaceutical Company Limited), Cambridge, MA, USA

12 Present address: Biogen Inc., Cambridge, MA, USA 
demonstrating improved survival outcomes using triplet regimens compared with doublet regimens [3-5]. This approach has demonstrated benefit both as induction prior to autologous stem cell transplantation (SCT) $[3,6,7]$ and in transplant-ineligible patients [5, 8-10]. Another important concept in the field of myeloma has been the increasing use of continuous therapy until disease progression, referred to variably as maintenance therapy or continued initial therapy [11-17]. The SWOG S0777 trial demonstrated prolonged overall survival (OS) when the proteasome inhibitor bortezomib was combined with lenalidomide and dexamethasone (VRd) in transplant-eligible and transplantineligible patients with NDMM [5]. In addition to the results of this trial, a recent meta-analysis has demonstrated the beneficial effect of proteasome inhibitors as part of induction therapy [7], leading to VRd being one of the current standards of care for the initial therapy of NDMM [5]. Bortezomib has shown some benefit as maintenance and/or consolidation therapy in some phase 3 trials [18-20]; however, the parenteral administration and risk of peripheral neuropathy (PN) limits its long-term use [15]. Therefore, the need for a convenient and well-tolerated proteasome inhibitor-based frontline therapy that can be dosed for an extended duration of time while providing sustained, deep responses with minimal late-onset or cumulative toxicity remains an unmet need. This is particularly important for subgroups with high unmet need, including the elderly.

The oral proteasome inhibitor ixazomib is approved in more than 60 countries, in combination with lenalidomide and dexamethasone (Rd), for patients with $\mathrm{MM}$ who have received at least one prior therapy [21]. The oral administration combined with the tolerability profile of ixazomib reported in patients with relapsed/refractory MM [22-30] demonstrates the opportunity for a proteasome inhibitorbased induction therapy and maintenance therapy that is convenient to administer, yet has a favorable toxicity profile, with limited neurologic toxicity and no long-term or late-onset toxicities. Indeed, recent results from the TOURMALINE-MM3 study demonstrate that 2-year maintenance with single-agent ixazomib, post SCT, significantly prolongs progression-free survival (PFS) with a low discontinuation rate [31].

We previously reported the results of a phase $1 / 2$ study assessing the all-oral triplet regimen of weekly ixazomib plus Rd (IRd) as induction therapy in patients with NDMM [24]. Patients received up to 12 cycles of IRd induction therapy followed by long-term single-agent ixazomib maintenance. Patients considered eligible for autologous SCT could withdraw from the study and proceed to SCT after six cycles of IRd induction. The recommended phase 2 dose of ixazomib was determined as $4 \mathrm{mg}$ weekly, and weekly IRd induction was shown to be active and generally well tolerated in NDMM [24]. The limited follow-up at the time of the initial report (median of 14.3 months) precluded assessment of the benefits and toxicity associated with longterm ixazomib therapy. Here we report the long-term efficacy and safety of IRd induction therapy followed by single-agent ixazomib maintenance in patients with NDMM who did not proceed to SCT.

\section{Subjects and methods}

\section{Study design}

This open-label, dose-escalation, phase $1 / 2$ study evaluated the safety, tolerability, and efficacy of weekly oral ixazomib combined with $\mathrm{Rd}$, followed by single-agent ixazomib maintenance, in patients with NDMM. Patients were enrolled at 10 sites in the United States between November 22, 2010 and February 28, 2012. The study was performed in accordance with the International Conference on Harmonization Guidelines for Good Clinical Practice and appropriate regulatory requirements, and with approval of Institutional Review Boards at individual enrolling institutions. The study was registered at www.clinicaltrials.gov as NCT01217957.

Patients aged 18 years or older with NDMM were enrolled. Patients required measurable disease, Eastern Cooperative Oncology Group performance status of $0-2$, and adequate hematologic, hepatic, and renal function. Detailed eligibility criteria are provided in Supplementary Table S1. Patients with: grade $\geq 2 \mathrm{PN}$; major surgery or infection requiring antibiotics within 14 days; uncontrolled cardiovascular conditions, including uncontrolled hypertension, uncontrolled cardiac arrhythmias, symptomatic congestive heart failure, unstable angina, or myocardial infarction within the past 6 months; prior deep vein thrombosis; prolonged QT interval; and known human immunodeficiency virus or hepatitis infections were excluded. All patients provided written, informed consent prior to participation in the trial.

\section{Treatment}

During induction, ixazomib was administered orally on days 1,8 , and 15 of a 28 -day cycle along with standard doses of lenalidomide ( $25 \mathrm{mg}$ daily on days 1-21) and dexamethasone ( $40 \mathrm{mg}$ weekly) for up to 12 cycles. Dose modifications of all three drugs were permitted for toxicities suspected to be related to the specific drugs. Relative dose intensity (RDI) over the course of treatment was determined, and was defined as:

$$
R D I=100 \times\left(\frac{\text { total amount of dose taken }}{\text { total planned dose over treated cycles }}\right)
$$


Where the total planned dose was calculated by:

$$
\begin{aligned}
\text { Total planned dose }= & (\text { dose planned at enrollment } \\
& \times \text { number of planned doses per cycle } \\
& \times \text { the number of treated cycles })
\end{aligned}
$$

The number of planned doses per cycle was 3 for ixazomib, 21 for lenalidomide, and 4 for dexamethasone. Patients were allowed to interrupt therapy for stem cell collection any time after three cycles of induction and to proceed to SCT after 6 cycles at the discretion of the treating physician. Patients who proceeded to SCT did not receive further ixazomib therapy and are not included in the present analysis. Patients who completed 12 cycles of IRd induction therapy could proceed to maintenance with single-agent ixazomib, given at the last tolerated dose during induction. Patients discontinued the study for progressive disease (PD) or unacceptable toxicities not controlled with dose modifications.

\section{Objectives}

The primary objectives were to determine the combined rate of complete response (CR) and very good partial response (VGPR), and the tolerability and toxicity of IRd in patients with NDMM. The secondary objectives included determination of overall response rate (ORR; at least partial response $[\geq P R]$ ), rates of individual response categories, measures of response durability (time to response, response duration, time to progression, and PFS), and OS.

\section{Assessments}

Adverse events (AEs) were graded using the National Cancer Institute's Common Terminology Criteria for AEs, version 4.02. Myeloma disease response was assessed by the investigators in accordance with the International Myeloma Working Group uniform criteria, incorporating additional categories of minimal response and near CR [32-34]. All responses were reviewed by the sponsor for consistency with the response criteria. Patients proceeding to SCT and those stopping treatment for reasons other than PD had disease assessments at the end of treatment and every 16 weeks thereafter. Patients who progressed had survival assessments every 16 weeks. Cytogenetic testing was conducted per institutional standard at local laboratories in this study; high-risk cytogenetic abnormalities were defined as any of del $(17 / 17 \mathrm{p}), \mathrm{t}(4 ; 14)$, and $\mathrm{t}(14 ; 16)$. Minimal residual disease (MRD) assessment was undertaken in all patients undergoing a subsequent bone marrow examination for response analysis (primarily $\mathrm{CR}$ confirmation) by multiparametric flow cytometry. The sensitivity of MRD assessment was $10^{-4}$. Patients enrolled in the phase 2 portion of the study completed quality of life (QoL) assessment at screening, at the start of each treatment cycle, and at the end of therapy, using the European Organisation for the Research and Treatment of Cancer Quality of Life Questionnaire C30 (EORTC-QLQ-C30) instrument.

\section{Statistical analysis}

The study design tested the null hypothesis $\mathrm{H}_{0}$ : $\mathrm{CR}+$ VGPR rate $=0.35$, and the alternative hypothesis of $\mathrm{H}_{1}$ : $\mathrm{CR}+\mathrm{VGPR}$ rate $>0.35$. With $80 \%$ power to reject $\mathrm{H}_{0}$ if the true CR + VGPR rate is $\geq 0.5$ and a one-sided significance level of alpha $=0.1$, the required sample size was 48 .

\section{Results}

\section{Patients}

A total of 65 patients were enrolled, 15 to the phase 1 portion of the trial and 50 to the phase 2 portion; a total of 53 patients received ixazomib $4 \mathrm{mg}$, the phase 2 dose. Among these 65 patients, 23 proceeded to SCT and discontinued induction therapy after a median of six cycles. The remaining 42 patients continued on therapy. Among these 42 patients, 17 patients discontinued during the induction phase, due to various reasons including: AEs ( $n=9 ; 14 \%$ of total population, $N=65$ ), patient withdrawal ( $n=4 ; 6 \%$ of total population, $N=65)$, PD $(n=2 ; 3 \%$ of total population, $N=65)$, unsatisfactory response $(n=1$; $2 \%$ of total population, $N=65)$, and other reason $(n=1$; $2 \%$ of total population, $N=65$ ). The remaining 25 patients completed 12 cycles of induction with IRd and continued to maintenance with single-agent ixazomib. At the data cutoff for the present analysis (median follow-up 55 months), 5 patients remained on treatment; 20 patients had discontinued during the ixazomib maintenance phase due to PD $(n=19)$ and patient withdrawal $(n=1)$. Baseline characteristics of the entire trial cohort as well as the 42 patients who did not proceed to SCT and the 25 patients who received maintenance are shown in Table 1.

\section{Disease response and survival}

The best confirmed ORR for all 64 response-evaluable patients (1 patient was not evaluable due to having no postbaseline assessment) was $88 \%$, including $58 \%$ of patients with $\geq$ VGPR and $23 \%$ with a CR (including stringent CR) (Table 2). Among the 41 response-evaluable patients who did not proceed to SCT, the ORR was $80 \%$, including a $63 \% \geq \mathrm{VGPR}$ rate and a $32 \% \mathrm{CR}$ rate. Among the 25 patients who received maintenance therapy, $8(32 \%)$ had a deepening of their response during maintenance (Fig. 1a). 
Table 1 Baseline demographics and disease characteristics of all patients, those who did not receive SCT, and those who proceeded to maintenance

\begin{tabular}{|c|c|c|c|}
\hline & Total $(N=65)$ & $\begin{array}{l}\text { Patients who did not } \\
\text { proceed to SCT }(N=42)\end{array}$ & $\begin{array}{l}\text { Patients who received } \\
\text { maintenance }(N=25)\end{array}$ \\
\hline Median age, years (range) & $66(34-86)$ & $68(34-86)$ & $69(34-77)$ \\
\hline Age $\geq 65$ years, $n(\%)$ & $34(52)$ & $26(62)$ & $16(64)$ \\
\hline Age $\geq 75$ years, $n(\%)$ & $12(18)$ & $10(24)$ & $4(16)$ \\
\hline Male, $n(\%)$ & $36(55)$ & $23(55)$ & $14(56)$ \\
\hline \multicolumn{4}{|l|}{ Race, $n(\%)$} \\
\hline White & $52(80)$ & $33(79)$ & $18(72)$ \\
\hline Black or African American & $12(18)$ & $8(19)$ & $6(24)$ \\
\hline Asian & $1(2)$ & $1(2)$ & $1(4)$ \\
\hline \multicolumn{4}{|l|}{ ISS disease stage at diagnosis, $n(\%)$} \\
\hline I & $28(43)$ & $17(40)$ & $14(56)$ \\
\hline II & $28(43)$ & $18(43)$ & $10(40)$ \\
\hline III & $9(14)$ & 7 (17) & $1(4)$ \\
\hline \multicolumn{4}{|l|}{ MM subtype, $n(\%)$} \\
\hline $\operatorname{IgG}$ & $44(68)$ & $27(64)$ & $15(60)$ \\
\hline $\operatorname{Ig} \mathrm{A}$ & $14(22)$ & $10(24)$ & $5(20)$ \\
\hline $\operatorname{IgD}$ & $1(2)$ & $1(2)$ & $1(4)$ \\
\hline Light chain & $6(9)$ & $4(10)$ & $4(16)$ \\
\hline Median creatinine clearance, $\mathrm{mL} / \mathrm{min}$ (range) & $81.4(27.8-167.2)$ & $77.0(28.0-167.0)$ & $79.0(46.0-167.0)$ \\
\hline High-risk cytogenetic abnormalities ${ }^{\mathrm{a}}, n(\%)$ & $5(8)$ & $3(7)$ & $2(8)$ \\
\hline del 17 & $2(3)$ & $1(3)$ & $1(4)$ \\
\hline $\mathrm{t}(4 ; 14)$ & $1(2)$ & $1(3)$ & 0 \\
\hline $\mathrm{t}(14 ; 16)$ & $2(3)$ & $2(5)$ & $1(4)$ \\
\hline
\end{tabular}

ISS International Staging System, MM multiple myeloma, SCT stem cell transplantation

${ }^{a}$ High-risk cytogenetic abnormalities included: del 17/17p, $\mathrm{t}(4 ; 14)$, and/or $\mathrm{t}(14 ; 16)$ detected by fluorescence in situ hybridization or metaphase cytogenetics

The kinetics of response during induction and maintenance are shown in Fig. 1b-d. Ninety-two percent of patients enrolled in the study had cytogenetic results and an evaluable response assessment. In the overall population, 5 patients had high-risk cytogenetic abnormalities; 1 achieved a CR and 3 achieved a PR (1 was not confirmed); these patients were in the subgroup that did not proceed to SCT. Of these 5 patients, 2 continued into the maintenance phase, during which their best response was CR and PR in 1 patient each. Sixteen of $64(25 \%)$ response-evaluable patients were assessed for MRD, of whom 9 had a best confirmed response of $\geq \mathrm{CR}$. Eight patients were found to be negative for MRD. Therefore, in the total study population, 8 of 64 response-evaluable patients $(12.5 \%)$ were MRD-negative.

With a median follow-up of 55 months, median PFS was 35.4 months (95\% confidence interval [CI], 17.84-44.12), 29.4 months (95\% CI, 17.71-41.13), and 37.2 months (95\% CI, 20.93-46.00) in the total population, in those who did not proceed to SCT, and in those who received maintenance therapy, respectively (Fig. 2). Median OS was not estimable (NE) in any of the three cohorts; however, given the duration of follow-up, estimates of long-term survival are feasible. The 4-year OS rates were 84,82 , and $92 \%$ in the total population, those who did not proceed to SCT, and those who received maintenance therapy, respectively (Table 2). Among all 34 elderly patients ( $\geq 65$ years), the median PFS was 21.4 months (95\% CI, 13.37-46.00), and the 4-year PFS rate was $30 \%$. For elderly patients who did not proceed to SCT $(n=26)$ and who received maintenance therapy $(n=16)$, the median PFS was 21.4 months $(95 \%$ CI, 12.91-46.00) and 37.5 months (95\% CI, 15.44-NE), respectively.

\section{Treatment exposure and safety profile}

At data cutoff, with 5 (8\%) patients remaining on treatment, patients in the overall population had received a median of 7 cycles (range 1-73) (Table 2). The median RDI was 96.3, 88.3 , and $92.5 \%$ for ixazomib, lenalidomide, and dexamethasone, respectively. For the 42 patients who did not proceed to SCT, the median number of cycles received was 17 (range 1-73), and median RDI was 96.3, 90.0, and $83.3 \%$ for ixazomib, lenalidomide, and dexamethasone, 
Table 2 Treatment outcomes and exposure of all response-evaluable patients, those who did not proceed to SCT, and those who received maintenance

\begin{tabular}{|c|c|c|c|}
\hline & $\begin{array}{l}\text { All patients } \\
(N=64)\end{array}$ & $\begin{array}{l}\text { Patients who did not } \\
\text { proceed to SCT }(N=41)\end{array}$ & $\begin{array}{l}\text { Patients who received } \\
\text { maintenance }(N=25)\end{array}$ \\
\hline \multicolumn{4}{|l|}{ Clinical outcome } \\
\hline \multicolumn{4}{|l|}{ Best confirmed response } \\
\hline ORR $(\mathrm{CR}+\mathrm{VGPR}+\mathrm{PR})$ & $56(88)$ & $33(80)$ & $25(100)$ \\
\hline$\geq$ VGPR & $37(58)$ & $26(63)$ & $19(76)$ \\
\hline $\mathrm{CR}$ & $15(23)$ & $13(32)$ & $11(44)$ \\
\hline sCR & $6(9)$ & $4(10)$ & $4(16)$ \\
\hline PR & $41(64)$ & $20(49)$ & $14(56)$ \\
\hline VGPR & $22(34)$ & $13(32)$ & $8(32)$ \\
\hline Near complete response & $5(8)$ & $4(10)$ & $3(12)$ \\
\hline Minimal response & $3(5)$ & $3(7)$ & 0 \\
\hline SD & $3(5)$ & $3(7)$ & 0 \\
\hline PD & 0 & 0 & 0 \\
\hline Median time to best response $\geq \mathrm{VGPR}$, months ${ }^{\mathrm{a}}$ & 4.9 & 6.6 & 8.5 \\
\hline Median time to best response sCR/CR, months ${ }^{\mathrm{b}}$ & 5.6 & 5.6 & 5.8 \\
\hline Median PFS, months (95\% CI) & $35.4(17.84,44.12)$ & $29.4(17.71,41.13)$ & $37.2(20.93,46.00)$ \\
\hline Median follow-up for OS, months & 56.3 & 55.2 & 56.4 \\
\hline Median OS, months & $\mathrm{NE}$ & $\mathrm{NE}$ & NE \\
\hline \multicolumn{4}{|l|}{ Landmark OS rate, $\%$} \\
\hline 1 year & 94 & 90 & 100 \\
\hline 2 years & 89 & 87 & 100 \\
\hline 4 years & 84 & 82 & 92 \\
\hline \multicolumn{4}{|l|}{ Treatment exposure } \\
\hline Median cycles of ixazomib received, $n$ (range) & $7(1-73)$ & $17(1-73)$ & $41(15-73)$ \\
\hline \multicolumn{4}{|l|}{ Cycles of ixazomib received, $n(\%)$} \\
\hline$\geq 8$ & $32(49)$ & $29(69)$ & $25(100)$ \\
\hline$\geq 12$ & $26(40)$ & $25(60)$ & $25(100)$ \\
\hline$\geq 16$ & $24(37)$ & $24(57)$ & $24(96)$ \\
\hline \multicolumn{4}{|l|}{ Median relative dose intensity ${ }^{\mathrm{c}}, \%$} \\
\hline Ixazomib & 96.3 & 96.3 & 96.6 \\
\hline Lenalidomide & 88.3 & 90 & 93.7 \\
\hline Dexamethasone & 92.5 & 83.3 & 83.3 \\
\hline Patients remaining on treatment, $n(\%)$ & $5(8)$ & $5(12)$ & $5(20)$ \\
\hline
\end{tabular}

Patients who proceeded to SCT did not receive further ixazomib therapy and the best response reported did not include response post SCT $C I$ confidence interval, $C R$ complete response, $N E$ not estimable, $O R R$ overall response rate, $O S$ overall survival, $P D$ progressive disease, $P F S$ progression-free survival, $P R$ partial response, $s C R$ stringent $C R, S C T$ stem cell transplantation, $S D$ stable disease, VGPR very good PR

${ }^{\mathrm{a}} n=37,26$, and 19 for all patients, those who did not receive SCT, and those who proceeded to maintenance, respectively

${ }^{\mathrm{b}} n=15,13$, and 11 for all patients, those who did not receive SCT, and those who proceeded to maintenance, respectively

${ }^{c}$ Relative dose intensity $=100 \times$ (total amount of dose taken $\div$ total planned dose over treated cycles), where total planned dose was calculated by (dose planned at enrollment $\times$ number of planned doses per cycle $\times$ the number of treated cycles). Number of planned doses per cycle was 3 for ixazomib, 21 for lenalidomide, and 4 for dexamethasone

respectively. Among the 25 patients receiving ixazomib maintenance, the median duration of therapy was 41 cycles (range 15-73) and median RDI for ixazomib over the entire treatment period was $96.6 \%$.

The overall safety profile of IRd induction followed by single-agent ixazomib maintenance is summarized in
Table 3. Among the 42 patients who did not receive SCT, $86 \%$ experienced at least one grade $\geq 3$ treatment-emergent $\mathrm{AE}$, serious AEs were reported in $52 \%$, and 2 patients died on study. Among the 25 patients receiving maintenance, $68 \%$ had at least one grade $\geq 3$ treatment-emergent $\mathrm{AE}$ during IRd induction, and the incidence was $48 \%$ during the 

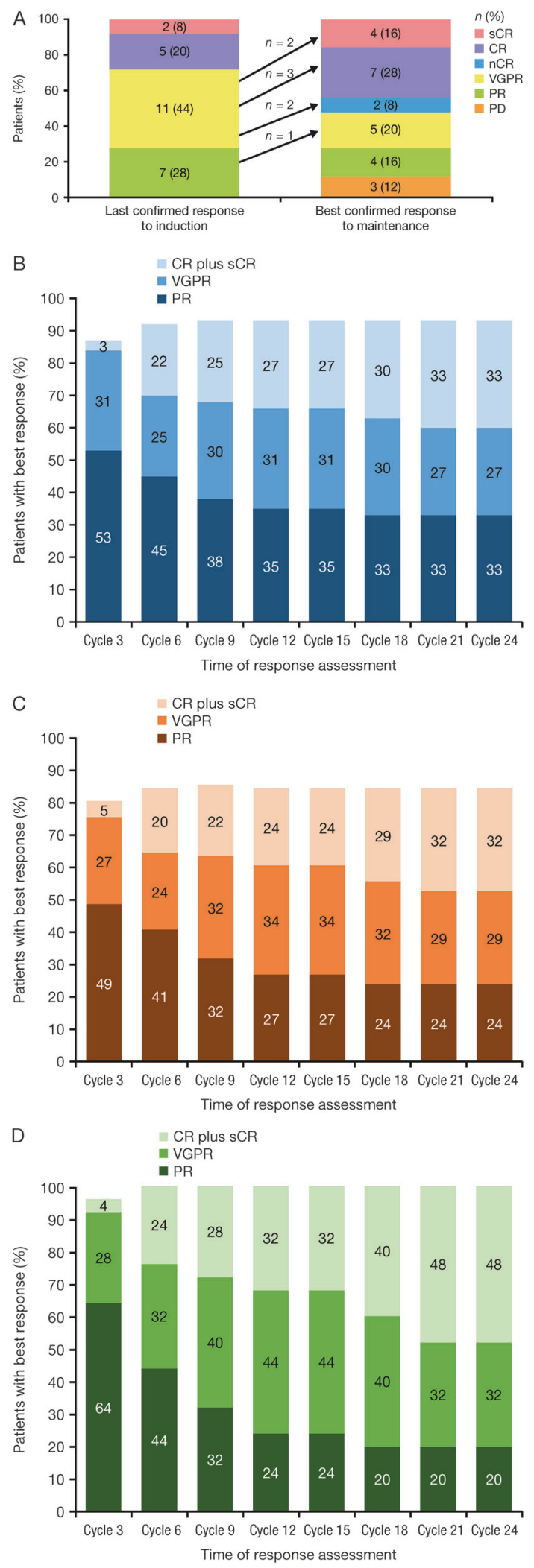

single-agent ixazomib maintenance phase. Tolerability in elderly patients (aged $\geq 65$ years) was similar to that in the overall study population; the two on-study deaths that
Fig. 1 Changes in response rates during induction and maintenance. a Deepening of response during the maintenance phase, $\mathbf{b}$ kinetics of response during induction and maintenance in all patients $(N=64)$, $\mathbf{c}$ kinetics of response during induction and maintenance in patients who did not proceed to stem cell transplantation $(N=41)$, and $\mathbf{d}$ kinetics of response during induction and maintenance in patients who received maintenance $(N=25)$

occurred were in patients aged $\geq 65$ years who did not receive maintenance therapy (Table S2). The most common grade $\geq 3$ treatment-emergent AEs in the overall population $(n=65)$ included neutropenia $(22 \%)$, thrombocytopenia $(11 \%)$, diarrhea $(9 \%)$, and fatigue $(9 \%)$ (Table 4$)$. In patients who received maintenance, the overall incidence of grade $\geq 3$ treatment-emergent AEs was higher during the IRd induction phase versus maintenance (68\% versus $48 \%$ ).

Among the 42 patients who did not proceed to SCT, treatment-emergent PN of any type was reported in 19 (45\%) patients. Most PN events were low-grade, with 17 patients reporting grade 1 or $2 \mathrm{PN}$; only 2 patients reported grade $3 \mathrm{PN}$. Among the 25 patients receiving maintenance, there were no cases of new-onset grade 3 or higher PN. There was 1 new primary malignancy, which was not considered related to treatment (squamous cell carcinoma of the skin on the thigh).

Among the patients not proceeding to SCT, AEs led to dose reductions in 27 (64\%) patients, of whom 9 (21\%), 19 $(45 \%)$, and $16(38 \%)$ required ixazomib, dexamethasone, and lenalidomide dose reductions, respectively. Overall, the most common treatment-emergent AEs leading to dose reduction were fatigue $(19 \%)$, PN (12\%), diarrhea, insomnia, and weight increase (10\% each). AEs leading to discontinuation of study treatment were reported in 9 patients. There were no treatment discontinuations during the maintenance phase (Table 3). Data on QoL were obtained from baseline in patients enrolled to the phase 2 portion of the study. Mean global health status/QoL score from the EORTC-QLQ-C30 instrument over the course of treatment is shown in Supplementary Figure 1.

\section{Discussion}

Proteasome inhibitors are a cornerstone of therapy across the MM treatment paradigm [35], and the combination of a proteasome inhibitor and an immunomodulatory drug remains a standard initial therapy for patients with NDMM $[3,5,6,9]$. The recent approval of ixazomib in combination with $\mathrm{Rd}$ [21] has enabled the development of an all-oral triplet regimen containing both a proteasome inhibitor and immunomodulatory drug, and initial data using this triplet in NDMM patients demonstrated excellent efficacy, safety, and tolerability [24]. The long-term follow-up data 

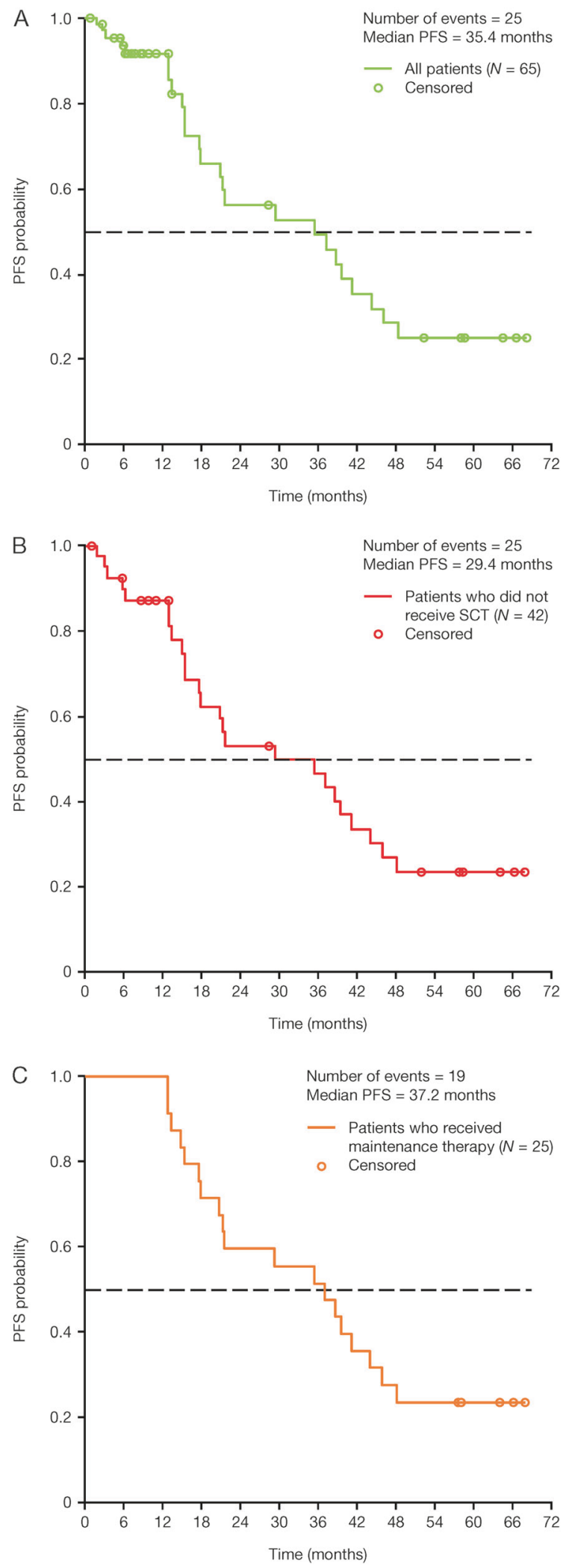

Fig. 2 Progression-free survival in a all patients*, $\mathbf{b}$ those who did not proceed to SCT and c those who received maintenance therapy.

*Patients who received SCT were censored at the time of SCT presented here not only confirm the efficacy of the all-oral IRd regimen for the initial therapy of $\mathrm{MM}$ but also demonstrate the ability to continue therapy among patients not proceeding to SCT, therefore supporting the overall feasibility, efficacy, and tolerability of long-term maintenance with a proteasome inhibitor, namely oral ixazomib.

In the present study, the IRd regimen was associated with an ORR of $88 \%(58 \% \geq \mathrm{VGPR}, 32 \% \mathrm{CR})$ in patients not proceeding to $\mathrm{SCT}$, and a median PFS of 35.4 months in the overall population. These results compare favorably with previous results with the standard-of-care regimen VRd. For example, in the SWOG S0777 trial, which included both transplant-ineligible and transplant-eligible $(69 \%)$ patients, treatment with VRd resulted in an ORR of $82 \%(44 \%$ $\geq$ VGPR) and a median PFS of 43 months [5]. Similarly, in the EVOLUTION study, which included a majority of transplant-eligible patients $(>80 \%)$ but also included transplant-ineligible NDMM patients, VRd was associated with an ORR of $85 \%$ (51\% $\geq$ VGPR) [9]. In the IFM2009 trial, which included transplant-eligible patients only, the ORR with VRd induction followed by lenalidomide maintenance was $97 \%$ ( $77 \% \geq$ VGPR) and the median PFS was 36 months [3]. The results with IRd in the present study are particularly notable in the context of these studies when it is considered that over one-third of patients discontinued early to receive SCT and more than half who continued the IRd regimen were aged $\geq 65$ years.

We previously reported on the lack of any adverse impact of this regimen on stem cell collection among patients going to transplant, allowing its use for the initial therapy of transplant-eligible patients [24]. The results reported here show IRd is also an attractive option for patients who are transplant-ineligible or do not desire transplant, as it allows for continued, effective treatment with the same regimen. In the current study, nearly twothirds of the patients opted not to go to transplant, which is not surprising since over half of the patients were aged $\geq 65$ years, and these patients stayed on therapy for varying durations of time. Among patients not proceeding to SCT, the ORR was $80 \%$, including a $\geq$ VGPR rate of $63 \%$, which is comparable to the overall cohort (88\% ORR and 58\% $\geq$ VGPR). Among these 41 patients, the median PFS was 29.4 months, and 4-year OS was $82 \%$, again highlighting the efficacy and durability of the IRd regimen when used as initial therapy for transplant-ineligible patients with NDMM. Among the patients aged $\geq 65$ years who did not proceed to transplant, the median PFS was 21.4 months, with a 4 -year OS of $28 \%$.

Importantly, in the present study, the IRd regimen was well tolerated in the overall population, in patients who did not proceed to SCT, and in elderly patients, with a similar, generally manageable toxicity profile reported, consistent with prior experience with ixazomib [22-27, 36]. The 
Table 3 Overall safety profile and most common AEs with IRd induction and single-agent ixazomib maintenance

\begin{tabular}{|c|c|c|c|c|}
\hline \multirow[b]{2}{*}{$n(\%)$} & \multirow[t]{2}{*}{$\begin{array}{l}\text { All patients } \\
(N=65)\end{array}$} & \multirow{2}{*}{$\begin{array}{l}\text { Patients who did } \\
\text { not proceed to } \\
\text { SCT }(N=42)\end{array}$} & \multicolumn{2}{|c|}{$\begin{array}{l}\text { Patients who received maintenance } \\
(N=25)^{\mathrm{a}}\end{array}$} \\
\hline & & & $\begin{array}{l}\text { AE onset in } \\
\text { cycles } 1-12 \\
\text { (IRd) }\end{array}$ & $\begin{array}{l}\text { AE onset in cycle } \\
13+\text { (single-agent } \\
\text { ixazomib) }\end{array}$ \\
\hline Any grade $\geq 3 \mathrm{AE}$ & $51(78)$ & $36(86)$ & $17(68)$ & $12(48)$ \\
\hline Any serious $\mathrm{AE}$ & $30(46)$ & $22(52)$ & $9(36)$ & $7(28)$ \\
\hline $\begin{array}{l}\text { AE leading to any study drug } \\
\text { dose reduction }\end{array}$ & $37(57)$ & $27(64)$ & $19(76)$ & $2(8)$ \\
\hline $\begin{array}{l}\text { AE leading to discontinuation of } \\
\text { any of the study drugs }\end{array}$ & $10(15)$ & $9(21)$ & 0 & 0 \\
\hline On-study deaths & $2(3)$ & $2(5)$ & 0 & 0 \\
\hline \multicolumn{5}{|c|}{ Most common AEs (in $>25 \%$ of the overall study population) } \\
\hline Diarrhea & $39(60)$ & $28(67)$ & $14(56)$ & $13(52)$ \\
\hline Fatigue & $39(60)$ & $27(64)$ & $18(72)$ & $2(8)$ \\
\hline Nausea & $36(55)$ & $24(57)$ & $12(48)$ & $8(32)$ \\
\hline PN NEC ${ }^{b}$ & $28(43)$ & $19(45)$ & $13(52)$ & $3(12)$ \\
\hline $\begin{array}{l}\text { Upper respiratory tract } \\
\text { infection }\end{array}$ & $28(43)$ & $19(45)$ & $9(36)$ & $9(36)$ \\
\hline Constipation & $26(40)$ & $17(40)$ & $13(52)$ & $2(8)$ \\
\hline Vomiting & $26(40)$ & $16(38)$ & $9(36)$ & $2(8)$ \\
\hline $\begin{array}{l}\text { Rashes eruptions and } \\
\text { exanthems }{ }^{\text {b }}\end{array}$ & $23(35)$ & $15(36)$ & $11(44)$ & $3(12)$ \\
\hline Back pain & $22(34)$ & $14(33)$ & $7(28)$ & $5(20)$ \\
\hline Peripheral edema & $22(34)$ & $14(33)$ & $10(40)$ & $3(12)$ \\
\hline Thrombocytopenia $^{c}$ & $23(35)$ & $16(38)$ & $4(16)$ & $4(16)$ \\
\hline Insomnia & $21(32)$ & $14(33)$ & $8(32)$ & $1(4)$ \\
\hline Cough & $21(32)$ & $17(40)$ & $8(32)$ & $3(12)$ \\
\hline Pain in extremity & $20(31)$ & $15(36)$ & $5(20)$ & $9(36)$ \\
\hline Dizziness & $19(29)$ & $15(36)$ & $6(24)$ & $3(12)$ \\
\hline Neutropenia $^{c}$ & $20(31)$ & $12(29)$ & $5(20)$ & 0 \\
\hline Pyrexia & $18(28)$ & $13(31)$ & $6(24)$ & $2(8)$ \\
\hline
\end{tabular}

$A E$ adverse event, $N E C$ not elsewhere classified, $P N$ peripheral neuropathy, $S C T$ stem cell transplantation ${ }^{\mathrm{a}}$ Data are split to represent AEs during IRd induction (cycles 1-12), and single-agent ixazomib maintenance; patients could have had a new-onset AE in both treatment periods

${ }^{\mathrm{b}}$ Data represent higher-level terms

${ }^{c}$ Pooled terms ability to continue treatment is particularly important for transplant-ineligible patients; here only 9 of the 42 patients who did not proceed to SCT had a treatment-emergent AE requiring discontinuation of any of the study drugs and both the ixazomib and lenalidomide RDIs were maintained during the course of the treatment. One of the advantages associated with ixazomib compared with bortezomib has been the relatively lower incidence of PN, particularly grade $\geq 3$ events. Across the entire trial, $\mathrm{PN}$ of any grade was seen in $43 \%$ of patients, with very few patients developing grade $\geq 3 \mathrm{PN}(6 \%)$. In contrast, VRd has been associated with grade $\geq 3 \mathrm{PN}$ in nearly $20 \%$ of patients in previous trials $[3,9]$. Richardson et al. reported sensory neuropathy, motor neuropathy, and neuropathic pain in 80,18 , and $32 \%$ of patients, respectively, including at grade 3 in 2, 2, and $3 \%$ of patients, respectively [37]. The rate of grade $\geq 3$ neurologic toxicity in the SWOG S0777 trial was 33\% [5].

Importantly, the results of this trial highlight the feasibility of single-agent ixazomib as maintenance therapy. Continuous therapy has become a preferred approach, with maintenance post transplant and continued treatment in elderly, non-transplant-eligible patients now routine [14]. Over half of the patients not proceeding to SCT continued on maintenance therapy with single-agent ixazomib. The benefit of single-agent ixazomib maintenance therapy is highlighted by the improvement in the $\geq \mathrm{CR}$ rate from $28 \%$ 
Table 4 Most common grade $\geq 3$ AEs (in $>5 \%$ of the overall population)

$$
\begin{array}{lll}
\begin{array}{l}
\text { All patients } \\
(N=65)
\end{array} & \begin{array}{l}
\text { Patients who did not } \\
\text { proceed to SCT }
\end{array} & \begin{array}{l}
\text { Patients who received maintenance } \\
(N=25)^{\mathrm{a}}
\end{array}
\end{array}
$$

\begin{tabular}{|c|c|c|c|c|}
\hline \multirow[b]{2}{*}{$n(\%)$} & & & & \\
\hline & & & $\begin{array}{l}\text { AE onset in } \\
\text { cycles } 1-12 \\
\text { (IRd) }\end{array}$ & $\begin{array}{l}\text { AE onset in cycle } \\
13+\text { (single-agent } \\
\text { ixazomib) }\end{array}$ \\
\hline Neutropenia ${ }^{\mathrm{b}}$ & $14(22)$ & $9(21)$ & $4(16)$ & $2(8)$ \\
\hline Thrombocytopenia $^{\mathrm{b}}$ & $9(14)$ & $7(17)$ & $2(8)$ & $1(4)$ \\
\hline Diarrhea & $6(9)$ & $4(10)$ & 0 & 0 \\
\hline Fatigue & $6(9)$ & $6(14)$ & $5(20)$ & 0 \\
\hline Back pain & $5(8)$ & $2(5)$ & $1(4)$ & 0 \\
\hline Dehydration & $5(8)$ & $5(12)$ & 0 & $1(4)$ \\
\hline Hypokalemia & $5(8)$ & $4(10)$ & $2(8)$ & $1(4)$ \\
\hline Lymphopenia & $6(9)$ & $4(10)$ & $3(12)$ & $1(4)$ \\
\hline Anemia & $4(6)$ & $4(10)$ & $2(8)$ & 0 \\
\hline Hypertension & $4(6)$ & $2(5)$ & $1(4)$ & $1(4)$ \\
\hline Hypophosphatemia & $4(6)$ & $4(10)$ & $3(12)$ & 0 \\
\hline Leukopenia & $5(8)$ & $5(12)$ & $1(4)$ & 0 \\
\hline $\begin{array}{l}\text { Rashes, eruptions, and } \\
\text { exanthems }{ }^{c}\end{array}$ & $4(6)$ & $4(10)$ & $3(12)$ & 0 \\
\hline $\mathrm{PN} \mathrm{NEC}^{\mathrm{c}}$ & $4(6)$ & $2(5)$ & 0 & 0 \\
\hline Pneumonia & $4(6)$ & $3(7)$ & $1(4)$ & $2(8)$ \\
\hline Vomiting & $4(6)$ & $1(2)$ & 0 & 0 \\
\hline
\end{tabular}$$
(N=42)
$$

$A E$ adverse event, $N E C$ not elsewhere classified, $P N$ peripheral neuropathy, $S C T$ stem cell transplantation

${ }^{a}$ Data are split to represent AEs during IRd induction (cycles 1-12), and single-agent ixazomib maintenance; patients could have had a new-onset $\mathrm{AE}$ in both treatment periods

${ }^{\mathrm{b}}$ Pooled terms

${ }^{\mathrm{c}}$ Data represent higher-level terms

at the start of maintenance to $44 \%$ as best response on maintenance (Fig. 1a), which translated into prolonged long-term outcomes. Of note, one-third of patients who received maintenance improved their response during the maintenance period. Importantly, when considering the feasibility of continuous therapy, single-agent ixazomib was well tolerated, with few treatment-emergent AEs reported during the maintenance phase and no patients discontinuing therapy during maintenance therapy due to AEs. The overall tolerability profile compares favorably to that observed with continuous Rd therapy in the FIRST trial [11] or lenalidomide maintenance following VRd induction in the SWOG S0777 trial [5]. For example, in the SWOG S0777 trial, $24 \%$ of patients required dose reduction of lenalidomide as maintenance, while dose reductions of ixazomib maintenance were required in only 3 of the 25 patients (12\%) who proceeded to maintenance, highlighting the ability to maintain the dose intensity of ixazomib maintenance therapy. The median duration of therapy with continuous Rd in the FIRST trial was 18.4 months, whereas in the present study patients who proceeded to maintenance received a median of 41 cycles of therapy ( 12 cycles of IRd induction and 29 cycles of ixazomib maintenance). Furthermore, in contrast to some reports with lenalidomide maintenance [38], no second primary malignancies considered related to therapy were noted with single-agent ixazomib maintenance in neither the current trial nor TOURMALINE-MM3 [31]. Recently published results of the TOURMALINE-MM3 trial support the use of 2-year fixed duration single-agent ixazomib as maintenance therapy following SCT. The trial showed that ixazomib was an efficacious, well-tolerated, once-weekly oral drug. After a median follow-up of 31 months, there was a 39\% improvement in PFS with ixazomib versus placebo (median PFS, 26.5 versus 21.3 months) and a greater rate of deepening of response versus placebo, with little toxicity and maintained QoL. Phase 3 trials of IRd versus placebo-Rd in transplantineligible NDMM patients (NCT01850524) and of ixazomib versus placebo maintenance in patients ineligible for SCT (NCT02312258) have completed accrual and the results are awaited.

In conclusion, the IRd combination offers a convenient all-oral regimen that combines the efficacy of a proteasome inhibitor and an immunomodulatory drug-based regimen for the treatment of NDMM with a well-tolerated and manageable toxicity profile, including a relatively low risk 
of PN, and the convenience of a reduced need for office visits. In patients not proceeding to SCT and in patients proceeding to maintenance therapy, the regimen can be continued long-term, with a manageable toxicity profile, and further allows for maintenance with single-agent ixazomib with no significant cumulative toxicities.

Acknowledgements The authors thank all patients included in this study and their families, as well as all physicians, research nurses, study coordinators, and research staff participating in this study. The authors also acknowledge Laura Webb, PhD, of FireKite, an Ashfield company, part of UDG Healthcare plc, for medical writing support, which was funded by Millennium Pharmaceuticals, Inc., Cambridge, MA, USA, a wholly owned subsidiary of Takeda Pharmaceutical Company Limited, and complied with Good Publication Practice-3 (GPP3) guidelines (Battisti WP, et al. Ann Intern Med. 2015; 163:461-4), and Renda Ferrari, PhD, (Millennium Pharmaceuticals, Inc.) for editorial support.

Author contributions: SKK: involved in study design, patient enrollment, data collection, data analysis, data interpretation, and manuscript writing. JGB, RN, SL, JPL, MH, AKS, PH, VR, RV, JLK, and SVR: involved in patient enrollment, data collection, and manuscript reviewing. DB: involved in study design, data collection, data analysis, data interpretation, and manuscript writing. EL: involved in data collection, data analysis, and manuscript writing. PGR: involved in study design, patient enrollment, data collection, data analysis, data interpretation, and manuscript writing.

\section{Compliance with ethical standards}

Conflict of interest SKK: consulting fees, paid to institution, from Celgene, Takeda, Janssen, KITE, Merck, Abbvie, Medimmune, Genentech, Oncopeptides, and Amgen. JGB: institutional research funding from Abbvie, Amgen, Bluebird, BMS, Celgene, Genentech, Glenmark, Janssen, Novartis, Poseida, Takeda, and Teva. RN: membership of advisory council or committee, consulting fees, and grants or funds from Takeda, Celgene, BMS, Amgen, and Janssen. SL: personal fees as a consultant for Millennium Pharmaceuticals Inc., Celgene, Novartis, BMS, Onyx, and Janssen, outside the submitted work. MH: membership of advisory council or committee for Pharmacyclics and Medimmune, honoraria from Celgene and Sanofi, consulting fees from Cellerant, and grants or funds from Takeda and Otsuka. AKS: consultant for: Amgen, Celgene, BMS, Janssen, Ono, and Takeda. PH: membership of advisory council or committee, and honoraria from Millennium/Takeda and Celgene. RV: honoraria from Takeda. JLK: grant from Millennium Pharmaceuticals, Inc. during the conduct of the study. Grants from Celgene, Merck, and Novartis, and personal fees from Millennium Pharmaceuticals, Inc., Celgene, Onyx, Spectrum, Novartis, and Janssen, outside the conduct of the study. DB and EL: employment, Millennium Pharmaceuticals, Inc., a wholly owned subsidiary of Takeda Pharmaceutical Company Limited. PGR: consulting fees from Takeda and Celgene. The remaining authors declare that they have no conflict of interest.

Ethical approval The study was performed in accordance with the International Conference on Harmonization, the Guidelines for Good Clinical Practice, appropriate regulatory requirements, and with approval of Institutional Review Boards at individual enrolling institutions.

Publisher's note: Springer Nature remains neutral with regard to jurisdictional claims in published maps and institutional affiliations.
Open Access This article is licensed under a Creative Commons Attribution 4.0 International License, which permits use, sharing, adaptation, distribution and reproduction in any medium or format, as long as you give appropriate credit to the original author(s) and the source, provide a link to the Creative Commons license, and indicate if changes were made. The images or other third party material in this article are included in the article's Creative Commons license, unless indicated otherwise in a credit line to the material. If material is not included in the article's Creative Commons license and your intended use is not permitted by statutory regulation or exceeds the permitted use, you will need to obtain permission directly from the copyright holder. To view a copy of this license, visit http://creativecommons. org/licenses/by/4.0/.

\section{References}

1. Kumar SK, Rajkumar V, Kyle RA, van Duin M, Sonneveld P, Mateos MV, et al. Multiple myeloma. Nat Rev Dis Prim. 2017;3:17046.

2. Mikhael JR, Dingli D, Roy V, Reeder CB, Buadi FK, Hayman $\mathrm{SR}$, et al. Management of newly diagnosed symptomatic multiple myeloma: updated Mayo Stratification of Myeloma and RiskAdapted Therapy (mSMART) consensus guidelines 2013. Mayo Clin Proc. 2013;88:360-76.

3. Attal M, Lauwers-Cances V, Hulin C, Leleu X, Caillot D, Escoffre $\mathrm{M}$, et al. Lenalidomide, bortezomib, and dexamethasone with transplantation for myeloma. N Engl J Med. 2017;376:1311-20.

4. Cavo M, Tacchetti P, Patriarca F, Petrucci MT, Pantani L, Galli $\mathrm{M}$, et al. Bortezomib with thalidomide plus dexamethasone compared with thalidomide plus dexamethasone as induction therapy before, and consolidation therapy after, double autologous stem-cell transplantation in newly diagnosed multiple myeloma: a randomised phase 3 study. Lancet. 2010;376:2075-85.

5. Durie BG, Hoering A, Abidi MH, Rajkumar SV, Epstein J, Kahanic SP, et al. Bortezomib with lenalidomide and dexamethasone versus lenalidomide and dexamethasone alone in patients with newly diagnosed myeloma without intent for immediate autologous stem-cell transplant (SWOG S0777): a randomised, open-label, phase 3 trial. Lancet. 2017;389:519-27.

6. Cavo M, Pantani L, Pezzi A, Petrucci MT, Patriarca F, Di Raimondo F, et al. Bortezomib-thalidomide-dexamethasone (VTD) is superior to bortezomib-cyclophosphamide-dexamethasone (VCD) as induction therapy prior to autologous stem cell transplantation in multiple myeloma. Leukemia. 2015;29:2429-31.

7. Sonneveld P, Goldschmidt H, Rosinol L, Blade J, Lahuerta JJ, Cavo M, et al. Bortezomib-based versus nonbortezomib-based induction treatment before autologous stem-cell transplantation in patients with previously untreated multiple myeloma: a metaanalysis of phase III randomized, controlled trials. J Clin Oncol. 2013;31:3279-87.

8. San Miguel JF, Schlag R, Khuageva NK, Dimopoulos MA, Shpilberg O, Kropff M, et al. Bortezomib plus melphalan and prednisone for initial treatment of multiple myeloma. N Engl J Med. 2008;359:906-17.

9. Kumar S, Flinn I, Richardson PG, Hari P, Callander N, Noga SJ, et al. Randomized, multicenter, phase 2 study (EVOLUTION) of combinations of bortezomib, dexamethasone, cyclophosphamide, and lenalidomide in previously untreated multiple myeloma. Blood. 2012;119:4375-82.

10. Niesvizky R, Flinn IW, Rifkin R, Gabrail N, Charu V, Clowney $\mathrm{B}$, et al. Community-based phase IIIb trial of three UPFRONT bortezomib-based myeloma regimens. J Clin Oncol. 2015;33:3921-9.

11. Facon T, Dimopoulos MA, Dispenzieri A, Catalano JV, Belch A, Cavo M, et al. Final analysis of survival outcomes in the phase 3 
FIRST trial of up-front treatment for multiple myeloma. Blood. 2018;131:301-10.

12. Guglielmelli T, Palumbo A. Multiple myeloma: is a shift toward continuous therapy needed to move forward? Expert Rev Hematol. 2015;8:253-6.

13. Palumbo A, Gay F, Cavallo F, Di Raimondo F, Larocca A, Hardan I, et al. Continuous therapy versus fixed duration of therapy in patients with newly diagnosed multiple myeloma. J Clin Oncol. 2015;33:3459-66.

14. Lipe B, Vukas R, Mikhael J. The role of maintenance therapy in multiple myeloma. Blood Cancer J. 2016;6:e485.

15. Ludwig H, Durie BG, McCarthy P, Palumbo A, San Miguel J, Barlogie B, et al. IMWG consensus on maintenance therapy in multiple myeloma. Blood. 2012;119:3003-15.

16. Rossi A, Mark T, Jayabalan D, Christos P, Zafar F, Pekle K, et al. BiRd (clarithromycin, lenalidomide, dexamethasone): an update on long-term lenalidomide therapy in previously untreated patients with multiple myeloma. Blood. 2013;121:1982-5.

17. Niesvizky R, Jayabalan DS, Christos PJ, Furst JR, Naib T, Ely S, et al. BiRD (Biaxin [clarithromycin]/Revlimid [lenalidomide]/ dexamethasone) combination therapy results in high completeand overall-response rates in treatment-naive symptomatic multiple myeloma. Blood. 2008;111:1101-9.

18. Mellqvist UH, Gimsing P, Hjertner O, Lenhoff S, Laane E, Remes $\mathrm{K}$, et al. Bortezomib consolidation after autologous stem cell transplantation in multiple myeloma: a Nordic Myeloma Study Group randomized phase 3 trial. Blood. 2013;121:4647-54.

19. Sonneveld P, Schmidt-Wolf IG, van der Holt B, El Jarari L, Bertsch U, Salwender H, et al. Bortezomib induction and maintenance treatment in patients with newly diagnosed multiple myeloma: results of the randomized phase III HOVON-65/ GMMG-HD4 trial. J Clin Oncol. 2012;30:2946-55.

20. Sun CY, Li JY, Chu ZB, Zhang L, Chen L, Hu Y. Efficacy and safety of bortezomib maintenance in patients with newly diagnosed multiple myeloma: a meta-analysis. Biosci Rep. 2017;37: BSR20170304.

21. Millennium Pharmaceuticals Inc. NINLARO ${ }^{\circledR}$ (ixazomib) capsules, for oral use. United States Prescribing Information. 2016. https://www.ninlaro.com/prescribing-information.pdf; Accessed December 1, 2018.

22. Kumar S, Moreau P, Hari P, Mateos MV, Ludwig H, Shustik C, et al. Management of adverse events associated with ixazomib plus lenalidomide/dexamethasone in relapsed/refractory multiple myeloma. Br J Haematol. 2017;178:571-82.

23. Kumar SK, Bensinger WI, Zimmerman TM, Reeder CB, Berenson JR, Berg D, et al. Phase 1 study of weekly dosing with the investigational oral proteasome inhibitor ixazomib in relapsed/ refractory multiple myeloma. Blood. 2014;124:1047-55.

24. Kumar SK, Berdeja JG, Niesvizky R, Lonial S, Laubach JP, Hamadani M, et al. Safety and tolerability of ixazomib, an oral proteasome inhibitor, in combination with lenalidomide and dexamethasone in patients with previously untreated multiple myeloma: an open-label phase $1 / 2$ study. Lancet Oncol. 2014;15:1503-12.

25. Kumar SK, LaPlant BR, Reeder CB, Roy V, Halvorson AE, Buadi F, et al. Randomized phase 2 trial of ixazomib and dexamethasone in relapsed multiple myeloma not refractory to bortezomib. Blood. 2016;128:2415-22.

26. Moreau P, Masszi T, Grzasko N, Bahlis NJ, Hansson M, Pour L, et al. Oral ixazomib, lenalidomide, and dexamethasone for multiple myeloma. N Engl J Med. 2016;374:1621-34.

27. Richardson PG, Baz R, Wang M, Jakubowiak AJ, Laubach JP, Harvey RD, et al. Phase 1 study of twice-weekly ixazomib, an oral proteasome inhibitor, in relapsed/refractory multiple myeloma patients. Blood. 2014;124:1038-46.

28. Avet-Loiseau H, Bahlis NJ, Chng WJ, Masszi T, Viterbo L, Pour $\mathrm{L}$, et al. Ixazomib significantly prolongs progression-free survival in high-risk relapsed/refractory myeloma patients. Blood. 2017;130:2610-8

29. Mateos MV, Masszi T, Grzasko N, Hansson M, Sandhu I, Pour $\mathrm{L}$, et al. Impact of prior therapy on the efficacy and safety of oral ixazomib-lenalidomide-dexamethasone vs. placebo-lenalidomide-dexamethasone in patients with relapsed/refractory multiple myeloma in TOURMALINE-MM1. Haematologica. 2017;102:1767-75.

30. Richardson PG, Kumar S, Laubach JP, Paba-Prada C, Gupta N, Berg D, et al. New developments in the management of relapsed/ refractory multiple myeloma - the role of ixazomib. J Blood Med. 2017;8:107-21.

31. Dimopoulos MA, Gay F, Schjesvold F, Beksac M, Hajek R, Weisel $\mathrm{KC}$, et al. Oral ixazomib maintenance following autologous stem cell transplantation (TOURMALINE-MM3): a double-blind, randomised, placebo-controlled phase 3 trial. Lancet. 2018. https://doi.org/10.1016/S0140-6736(18)33003-4.

32. Richardson PG, Barlogie B, Berenson J, Singhal S, Jagannath S, Irwin $\mathrm{D}$, et al. A phase 2 study of bortezomib in relapsed, refractory myeloma. N Engl J Med. 2003;348:2609-17.

33. Durie BG, Harousseau JL, San Miguel J, Blade J, Barlogie B, Anderson $\mathrm{K}$, et al. International uniform response criteria for multiple myeloma. Leukemia. 2006;20:1467-73.

34. Blade J, Samson D, Reece D, Apperley J, Bjorkstrand B, Gahrton G, et al. Criteria for evaluating disease response and progression in patients with multiple myeloma treated by highdose therapy and haemopoietic stem cell transplantation. Myeloma Subcommittee of the EBMT. European Group for Blood and Marrow Transplant. Br J Haematol. 1998;102:111523.

35. Moreau P, Richardson PG, Cavo M, Orlowski RZ, San Miguel JF, Palumbo A, et al. Proteasome inhibitors in multiple myeloma: 10 years later. Blood. 2012;120:947-59.

36. Kumar SK, LaPlant B, Roy V, Reeder CB, Lacy MQ, Gertz MA, et al. Phase 2 trial of ixazomib in patients with relapsed multiple myeloma not refractory to bortezomib. Blood Cancer J. 2015;5: e338.

37. Richardson PG, Weller E, Lonial S, Jakubowiak AJ, Jagannath S, Raje NS, et al. Lenalidomide, bortezomib, and dexamethasone combination therapy in patients with newly diagnosed multiple myeloma. Blood. 2010;116:679-86.

38. Dimopoulos MA, Richardson PG, Brandenburg N, Yu Z, Weber DM, Niesvizky R, et al. A review of second primary malignancy in patients with relapsed or refractory multiple myeloma treated with lenalidomide. Blood. 2012;119:2764-7. 